\title{
Regression Equations to Determine the Stages of Electric Current in Electrical Discharge Machining (EDM) According to the Level of Desired Surface Roughness with Shortest Processing Time
}

\author{
Roche Alimin ${ }^{* 1}$, Didik Wahjudi ${ }^{1}$, Hariyanto Gunawan ${ }^{2}$, and Prayogo Putra Poernomo ${ }^{1}$ \\ ${ }^{1}$ Mechanical Engineering Department, Petra Christian University, Jl. Siwalankerto No.121-131, \\ Surabaya 60236, Indonesia. \\ ${ }^{2}$ Mechanical Engineering Department, Chung Yuan Christian University, 200 Chung Pei Road, \\ Chung Li District, Taoyuan City, Taiwan 32023, R.O.C.
}

\begin{abstract}
Electrical Discharge Machining (EDM) is one of the most common non-conventional machining processes used in the manufacturing of die and mold. In the process of EDM, practitioners usually face a problem, which is how to shorten process time and determine the point where the current should be changed so that the resulted surface roughness is not too high due to the use of large current at the beginning of the process. The purpose of this study is to determine the point when to change (reduce) the current in order to obtain the desired surface roughness and shortest processing time. From analysis of data, experiment was obtained some regression equations, those are: average surface roughness $\left(R_{a}=5424+0.698 I\right)$ which is used to find the final current to obtain the desired final surface roughness, peaks to valleys average roughness $\left(R_{z}=5.73+3.418 I\right)$ which is used to find the changing point for initial currentand duration of processing time $\left(t=10^{3.164+0.4714}\right)$ which is used to estimate the duration of processing time with the input of initial and final currents.
\end{abstract}

Keywords: EDM sinking parameters, electro-thermal machining process, quality engineering.

\section{Background}

In the manufacturing of mold and dies, It is often found in the form of sharp angles or small radii which is difficult to reach by conventional mill/lathe tools. To overcome this difficulty, Electrical Discharge Machining (EDM) is commonly used because, in EDM, the workpiece is eroded using small electric sparks instead of relative rotating motion between cutting tool and workpiece as in traditional machining. In the process of EDM, only the surface of the workpiece that is very close to the EDM electrode will be eroded. Thus, the obtained surface shape of the workpiece will always be the opposite of the shape of the electrode used.

${ }^{*}$ Corresponding author: ralimin@petra.ac.id 
In the process of EDM, practitioners face a problem to shorten process time and to determine the point where the current strength should be changed so that the resulted surface roughness is not too high due to the use of large current at the beginning of the process. Normally, the EDM process uses a large initial electric current. The goal is to speed up the process because the greater electric current the faster the process of erosion happens, but the rougher the surface results. On the other hand, finish surface roughness is affected by final electric current but if the surface is too rough because of effect from the previous initial electric current, the final electric current cannot fix the surface roughness as it should be as desired. Therefore, a minimum stock clearance is needed for a given finish surface roughness. Meanwhile, the minimum stock clearance is affected but two factors that are $\mathrm{Rz}$ (the result of the previous initial electric current) and desired/requested $\mathrm{Ra}$ of finish surface roughness. The purpose of this study is to determine the point when to change the current to obtain the desired surface roughness and processing duration.

\section{Literature review}

\subsection{Working principle of EDM}

EDM is an electro-thermal machining process [1] that could process electrically conductive materials by using precisely controlled sparks that occur between an electrode and workpiece in the presence of dielectric fluid. The electrode may be considered the cutting tool. The electrode must always be spaced away from workpiece by the distance required for sparking, knowing as sparking gap. The sparking occurs in high frequency, above $2000 \mathrm{~Hz}$. Each spark occurs between the closest point of the electrode and the workpiece. The spark removes material from both the electrode and workpiece, which increases the distance between the electrode and the workpiece at that point. This cause the next spark occurs at the next closest point between the electrode and workpiece.

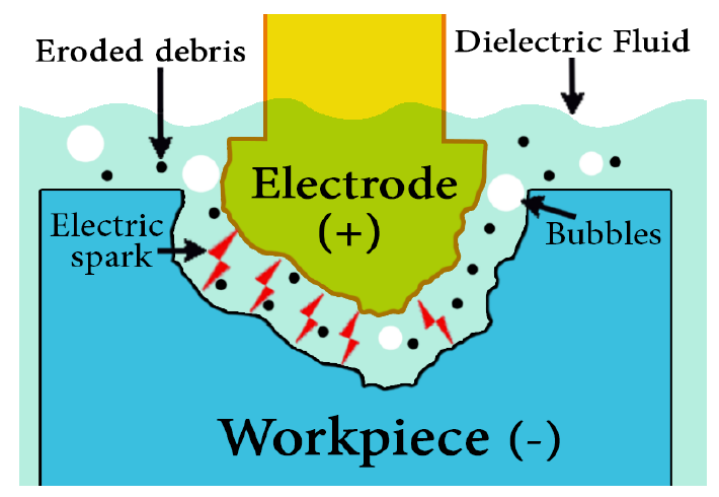

Fig. 1. The spark occurs between electrode and workpiece in ionized dielectric fluid [2].

Die-sinking EDM (used in this experiment) use hydrocarbon oil as dielectric fluid. The main characteristic of dielectric fluid is that it is an electrical insulator until enough electrical voltage is applied to cause it to change in an electrical conductor. These are the function of dielectric fluid used in EDM: controlling the sparking-gap spacing between the electrode and workpiece; cooling the heated material to form the EDM chip, and removing EDM chips from the sparking area [3]. 


\subsection{Rules of EDM parameter}

The most common performance measures for EDM are i) Material removal rate, measured in $\mathrm{mm}^{3} \mathrm{~min}^{-1}$; ii) Tool wear ratio, measured as tool removal rate to workpiece removal rate; and iii) Surface quality of the eroded cavity, measured in $\mu \mathrm{m}, \mathrm{Ra}[1]$.

The electrode tool polarity in the EDM process can be positive or negative, and this determines the direction of the electrical current, from or toward the electrode tool. The choice of polarity depends on many factors, including electrode tool and workpiece materials, current density and pulse length [2]. In this research, the electrode is negative polarity.

Because EDM is an electrical process, therefore some of EDM parameter related to the electrical parameter, such as voltage and current. In fixed pulse width (ratio of spark on time to spark off time), the higher of current the faster of machining process [4]. However in some material spark on time and off time also give contribute to MRR and surface roughness [5]. And if the current value per square $\mathrm{cm}$ is too high the speed will be slow down. Also, the higher current will produce rougher surface roughness [6]. Another way to increases the machining process is by using dry EDM. In this method, oxygen is used as dielectric fluid [7].

Usually, to increase the quality of surface roughness is used the small current, and as the drawback is the increase of process duration. Concerning in flushing technic also was developed in order to better surface roughness. This method varies pressure and volume. Higher flushing pressure will decrease the surface roughness, and become constant at the high value [8].

\subsection{Experiment design}

The experimental design is used as a method for designing a product or optimizing an existing product. Three basic principles in the design of experiments include [9]:

i. Randomization is a principled principle where randomisation aims to create one data with another. Randomization aims to prevent data from having a relationship that causes a dependency by randomly scaling the order of data from a given experiment.

ii. Replication is a repetition performed on an experiment provided that the object under study has the same characteristics, although it has different conditions and situations. This replication has the objective of estimating errors resulting from an experiment and obtaining an accurate calculation of the effects given by factors, either controlled or not.

iii. Blocking is a grouping done to minimize the effect of unwanted factors that can affect the response resulting from the experiment.

\subsection{One-way ANOVA}

Analysis of variance or commonly abbreviated ANOVA is a statistical analysis that is generally expressed in the form of tables used to investigate the influence of some parameters that have been determined against a particular response and to analyse the data obtained. The purpose of ANOVA is to know the effect of these parameters can stand alone or interact with other parameters.

One Way Analysis of Variance (one-way ANOVA) is a technique used to compare the average of two or more samples using the F distribution [9]. This test is only used for numerical data. The ANOVA test tests the null hypothesis of two or more factors taken from a population with the same mean value. ANOVA testing is usually used to test the differences between three factors or groups because the difference between two factors can be done by t-test method. One-way ANOVA testing can be done and can be trusted if it 
meets the assumptions or conditions that are normally distributed, data from independent samples, the variance of the population is the same, and identical.

The normal test is a test that aims to determine whether the residual data is normally distributed or not. Normal testing is performed using histogram test, normal P test, Chi Square test, Skewness, and Kurtosis.

Independent testing is intended to determine the relevance of data with other data or correlation. Independent testing can be done in three ways: Scatter Plot, Autocorrelation, and Runs Test. Data is said to be independent if the value of one observation is not influenced by the value of the other observations.

\section{Methodology}

In order to know the effect of current on the results of roughness and processing time, the current will be varied according to statistic principle. Experimental design is used to determine randomization, blocking, and number of repetitions.

All others involved EDM parameters (voltage, spark on time, spark off time, gapinitiation voltage, pulse cycle, polarity) are kept constant while current is varied [10]. The currents are set up in 10 level, start from $0.5 \mathrm{~A}$ up to $5 \mathrm{~A}$, with an increment of $0.5 \mathrm{~A}$, each done three repetitions. As output parameters that will be measured are surface roughness and processing time. The former is measured using surface roughness tester Mitutoyo SJ301. The latter is measured using built-in timer of EDM machine.

Pre-hardened steel material, coded SKD 11, is used as tested workpiece while copper is used as electrode material. Both workpiece and electrode surfaces are prepared with fine finishing grinding surface.

Figure 2. below is the photograph of the experiment. Electrode which has square cross section $10 \mathrm{~mm} \times 10 \mathrm{~mm}$ is used to make $1 \mathrm{~mm}$ depth of dented surfaces by EDM process. The process is conducted 30 times according to experiment design for 10-level, three repetitions. The experiment sequence is randomized using software based on variety of current.

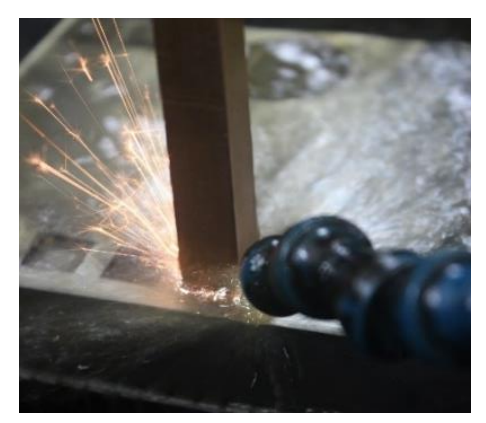

Fig. 2. EDM process on the experiment.

By using the result, in form of surface roughness and processing time corresponding with the value of electric current used, the regression analysis will be used to obtain the formulation so that at a certain point it is known as the point to change to the final current in order to obtain the possible shortest processing time [10].

\section{Result and discussion}

The data obtained is the processing time and the roughness of the workpiece surface. The average surface roughness and peak-valley data were processed using one-way ANOVA. 
Table 1. Data of the experiment.

\begin{tabular}{|c|c|c|c|c|c|}
\hline \multirow{2}{*}{$\begin{array}{c}\text { Standard } \\
\text { order }\end{array}$} & \multirow{2}{*}{$\begin{array}{l}\text { Run } \\
\text { order }\end{array}$} & $\begin{array}{l}\text { Electric } \\
\text { current }\end{array}$ & $\begin{array}{c}\text { Processing } \\
\text { time }\end{array}$ & $\begin{array}{c}\text { Average Surface } \\
\text { roughness }\end{array}$ & $\begin{array}{c}\text { Average } \\
\text { peak-valley }\end{array}$ \\
\hline & & (A) & $(\min )$ & $(\mu \mathrm{m})$ & $(\mu \mathrm{m})$ \\
\hline 1 & 13 & 0.5 & 1829 & 0.7 & 6.7 \\
\hline 2 & 21 & 1 & 702 & 1.1 & 8.7 \\
\hline 3 & 16 & 1.5 & 334 & 1.0 & 9.4 \\
\hline 4 & 9 & 2 & 62 & 2.3 & 12.4 \\
\hline 5 & 30 & 2.5 & 77 & 2.5 & 18.7 \\
\hline 6 & 24 & 3 & 49 & 2.9 & 18.8 \\
\hline 7 & 11 & 3.5 & 31 & 3.2 & 18.5 \\
\hline 8 & 4 & 4 & 13 & 3.4 & 18.5 \\
\hline 9 & 29 & 4.5 & 13 & 3.3 & 19.5 \\
\hline 10 & 7 & 5 & 10 & 3.9 & 21.6 \\
\hline 11 & 25 & 0.5 & 1177 & 0.8 & 6.8 \\
\hline 12 & 26 & 1 & 393 & 0.9 & 9.0 \\
\hline 13 & 18 & 1.5 & 373 & 1.2 & 9.4 \\
\hline 14 & 1 & 2 & 76 & 2.3 & 10.5 \\
\hline 15 & 2 & 2.5 & 83 & 2.3 & 18.0 \\
\hline 16 & 14 & 3 & 28 & 3.1 & 18.4 \\
\hline 17 & 5 & 3.5 & 41 & 2.7 & 18.7 \\
\hline 18 & 6 & 4 & 13 & 3.8 & 19.0 \\
\hline 19 & 27 & 4.5 & 14 & 3.4 & 19.6 \\
\hline 20 & 19 & 5 & 12 & 3.7 & 22.5 \\
\hline 21 & 8 & 0.5 & 1557 & 0.9 & 6.1 \\
\hline 22 & 20 & 1 & 474 & 1.1 & 8.9 \\
\hline 23 & 3 & 1.5 & 414 & 1.4 & 9.5 \\
\hline 24 & 23 & 2 & 97 & 2.7 & 11.5 \\
\hline 25 & 15 & 2.5 & 70 & 2.4 & 16.5 \\
\hline 26 & 17 & 3 & 55 & 2.8 & 18.5 \\
\hline 27 & 12 & 3.5 & 40 & 3.1 & 18.1 \\
\hline 28 & 10 & 4 & 13 & 3.5 & 19.0 \\
\hline 29 & 28 & 4.5 & 13 & 3.3 & 19.6 \\
\hline 30 & 22 & 5 & 10 & 4.1 & 21.8 \\
\hline
\end{tabular}




\subsection{Average surface roughness and peak-valley}

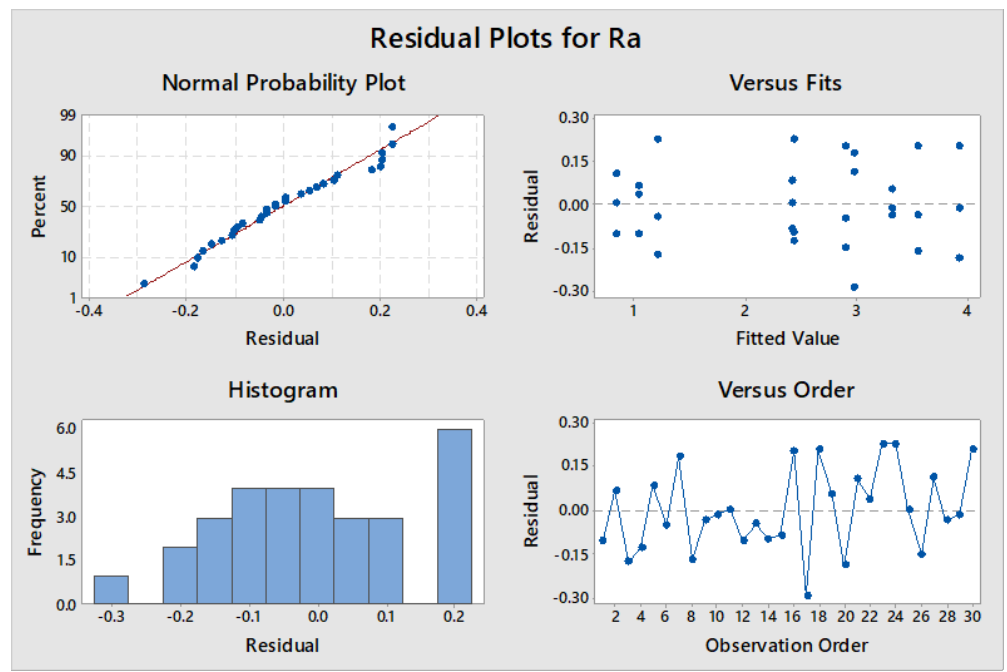

Fig. 3. Residual plot of average surface roughness.

Residual plot for $R a$, in Figure 3 shows that the normal probability plot of residual data is in the vicinity of a straight line. This shows that the distributed data is normal. From graphics versus fits, data spread and does not form a specific pattern. This shows that at each fitted value has a fairly homogeneous residual. From the histogram graph, the residual values can still be said to be normally distributed. From the chart versus order, the data does not form a pattern so that the data obtained is independent.

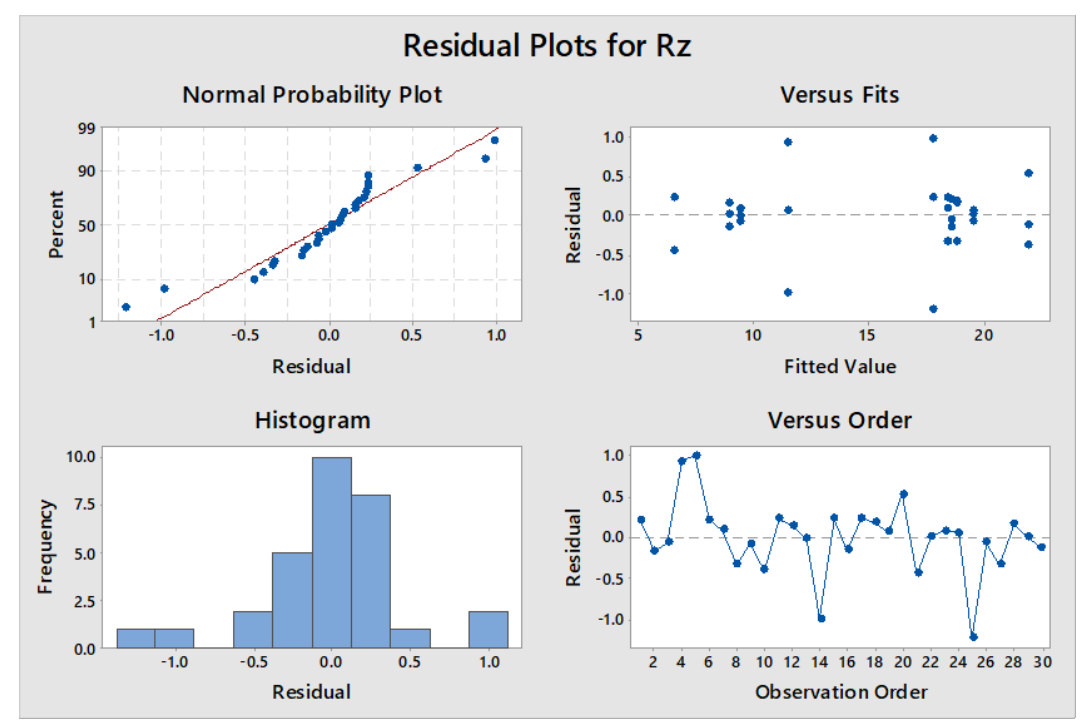

Fig. 4. Residual plot of average peak-valley. 
In the same manner, Figure 4 depicted graphics of residual plot for $R z$. The distributed data is normal and the data at each fitted value has a fairly homogeneous residual. The histogram graph shows that the residual values can still be said to be normally distributed. And the chart versus order shows that the data obtained is independent.

\subsection{ANOVA of average surface roughness and peak-valley.}

Table 2 indicates P-value less than 0.05. This shows that electric current strength significantly affects average surface roughness. The larger the current strength is used, the greater the average surface roughness. In the same manner, Table 3 shows that the electric current strength significantly affects the average peak-valve distance as well. The greater the current strength is used, the greater the peak-valley distance on average.

Table 2. ANOVA of average surface roughness $(R a)$.

\begin{tabular}{|l|l|l|l|l|l|}
\hline Source & DF & Adj SS & Adj MS & F-Value & P-Value \\
\hline Current & 9 & 32.3011 & 3.58902 & 128.98 & 0.000 \\
\hline Error & 20 & 0.5565 & 0.02783 & & \\
\hline Total & 29 & 32.8577 & & & \\
\hline
\end{tabular}

Table 3. ANOVA of average peak-valley (Rz).

\begin{tabular}{|l|r|r|r|r|r|}
\hline Source & DF & Adj SS & Adj MS & F-Value & P-Value \\
\hline Current & 9 & 804.076 & 89.3418 & 320.88 & 0.000 \\
\hline Error & 20 & 5.569 & 0.2784 & & \\
\hline Total & 29 & 809.645 & & & \\
\hline
\end{tabular}

\subsection{Processing time}

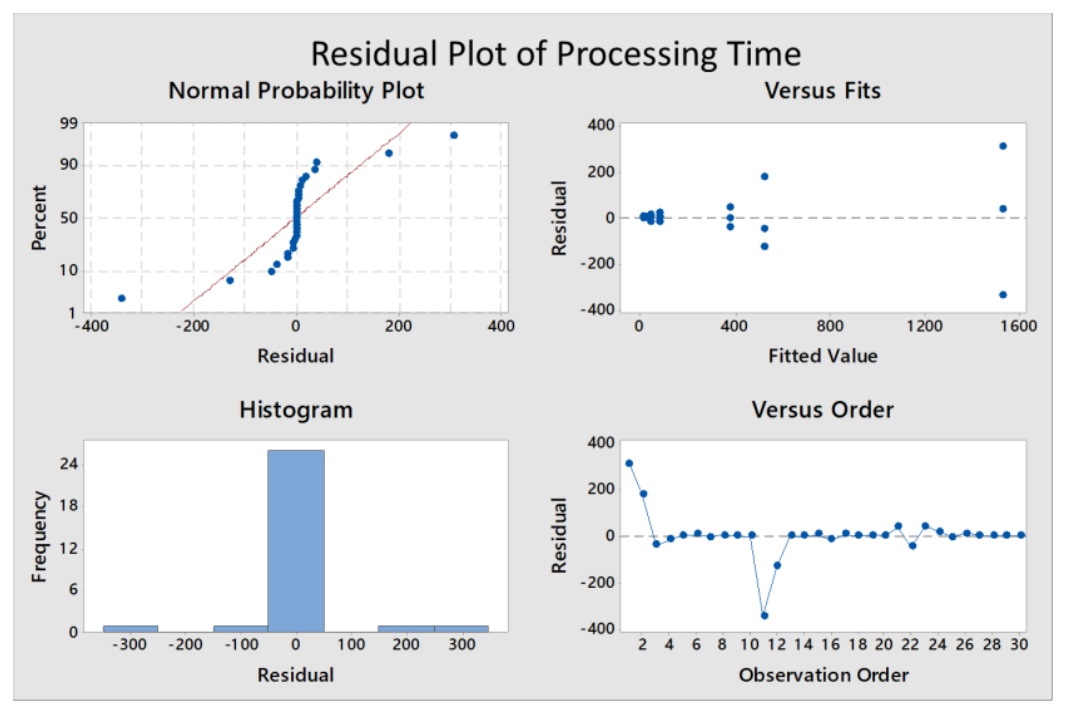

Fig. 5. Residual plot of processing time.

Figure 5 shows that the residual data is not distributed normal and each fitted value have different residual data. The histogram graph also indicates that the residual value is not normally distributed. The versus order chart also shows that the data obtained is not 
independent. From this analysis, it is necessary to transform the data in order to meet the assumptions underlying the analysis.

After transforming processing time $(t)$ become $\log t\left(t^{\prime}\right)$, residual plot of processing time is depicted in Figure 6 below.

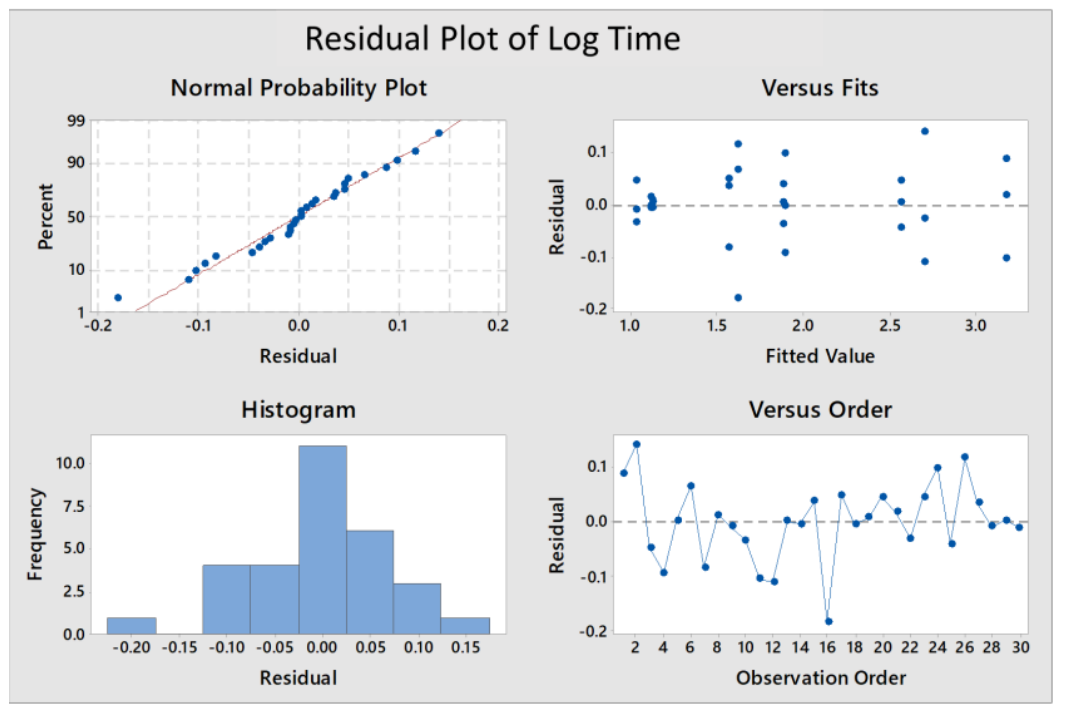

Fig. 6. Residual plot of processing time (transformed).

Table 4 shows the result of one-way ANOVA after the transformation. The P-value is less than 0.05 .

Table 4. ANOVA of processing time (transformed)

\begin{tabular}{|l|r|r|r|r|r|}
\hline Source & DF & Adj SS & Adj MS & F-Value & P-Value \\
\hline Current & 9 & 14.6462 & 1.62735 & 228.39 & 0.000 \\
\hline Error & 20 & 0.1425 & 0.00713 & & \\
\hline Total & 29 & 14.7887 & & & \\
\hline
\end{tabular}

This indicates that the electric current has a significant effect on the log processing time. The greater the current is used, the greater the log value of the processing time required.

\subsection{Applying the data}

The results of surface roughness and log length of processing time were processed by using linear regression. On the ANOVA analysis, the data of the processing time is less appropriate, therefore, log data duration of processing is used. The log result then was changed to the time equation of the process. From the results of the processing was obtained linear regression equation as follows

Regression equation for average surface roughness and average peak-valley:

$$
\begin{aligned}
& \quad R_{a}=5424+0.698 I \\
& R_{z}=5.73+3.418 I
\end{aligned}
$$

where: $\quad R_{a}=$ average surface roughness $(\mu \mathrm{m})$

$R_{z}=$ average peak-valley $(\mu \mathrm{m})$ 


$$
I=\text { electric current }(A)
$$

Regression equation for processing time:

$$
\begin{aligned}
& t^{\prime}=\log \mathrm{T}=3.164+0.4714 I \\
& t=10^{3.164+0.4714 I}
\end{aligned}
$$

where: $\quad t^{\prime}=\log$ of processing time

$t=$ processing time per $1 \mathrm{~mm}$ depth ( $\mathrm{mm} /$ minute)

$I=$ electric current $(A)$

The regression equations above can be used to estimate the average mean surface roughness, average peak-valve distance, time length of process or the current strength required if one of these variables is known.

\section{Conclusions}

Regression analysis of the experiment data produce some regression equations to determine the average surface roughness, that is $R_{a}=5424+0.698 I$, the average roughness of the average peaks, that is $R_{z}=5.73+3.418 I$ and the process length, that is $t^{\prime}=3.164+0.4714 \mathrm{I}$.

The average surface roughness regression equation is used to find the final current to obtain the desired final surface roughness. The regression equation for the average surface roughness of the average peaks is used to find the initial current change point. The process length regression equation is used to find the estimation of the length of time of the process corresponding with the input of initial and current currents.

\section{References}

1. A. Equbal, A.K. Sood. MIE. 1-2, $13: 1-6(2014)$. http://www.qipjournal.eu/index.php/MIE/article/view/339

2. J.E.A. Qubeiri, A. Saleh, A. Ziout, A.I. Mourad, M.H. Abidi, A. Elkaseer. Materials 12, 907:2-48(2019). https://www.mdpi.com/1996-1944/12/6/907/pdf

3. B. Fleming. The EDM: How to book. USA: Fleming publications (2005). p. 1-3. http://jimlund.org/blog/pics/EDM/The EDM_HowTo_Book_Electrical_Discharge_Machining_Ben_Fleming_2005.pdf

4. Suhardjono. Jurnal Teknik Mesin, 6, 1:14-19(2004). [in Bahasa Indonesia] http://jurnalmesin.petra.ac.id/index.php/mes/article/view/16207

5. S. Daneshmand, E.F. Kahrizi, E. Abedi, M.M. Abdolhosseini. Int. J. Electrochem. Sci., 8:3095-3104(2013). http://www.electrochemsci.org/papers/vol8/80303095.pdf

6. R.M. Bisono. Optimasi multi respon pada proses electrical discharge machining (EDM) sinking material baja perkakas DAC dengan menggunakan metode taguchigrey-fuzzy. [Multi-response optimization for electrical discharge machining (EDM) sinking material for DAC tool steel using taguchi-gray-fuzzy method.] [Thesis]. Program Magister Bidang Keahlian Rekayasa dan Sistem Manufaktur, Institut Teknologi Sepuluh Nopember Surabaya (2015). [in Bahasa Indonesia]. p.105. http://repository.its.ac.id/51819/2/2112201203-Master\%20Thesis.pdf

7. J. Tao, A.J. Shih, J. Ni. J. Manuf. Sci. Eng., 130, 1:1-9(2008) http://manufacturingscience.asmedigitalcollection.asme.org/article.aspx?articleid=1451 $\underline{997}$ 
8. M.M. Makenzi, B.W. Ikua. Proceedings of the 2012 Mechanical Engineering Conference on Sustainable Research and Innovation, Volume 4 (2012). p. 7-15. http://citeseerx.ist.psu.edu/viewdoc/download?doi=10.1.1.1027.4331\&rep=rep1\&type $=\mathrm{pdf}$

9. D.C. Montgomery. Design and analysis of experiments, 8th ed, USA: John Wiley \& Sons (2012). p. 12.

https://www.wiley.com/enau/Design+and+Analysis + of +Experiments $\% 2 C+8$ th+Edition-p-9781118146927

10. S. Sharifa, W. Safieia, A.F. Mansorb, M.H.M. Isac, R.M. Saada. Procedia Manufacturing 2:147-152(2015). https://cyberleninka.org/article/n/543153.pdf 